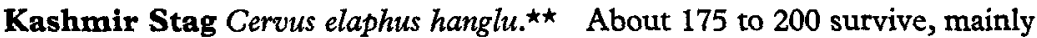
in the Dachigam sanctuary, with a few in other parts of Kashmir.

Kouprey Bos sauveli. $\star \star \star$ P. A forest ox, only discovered in 1937, restricted to two separate regions in northern Cambodia and numbering about 200 in all.

Seladang Bos gaurus hubbacki. $\star \star$ P. A wild ox occurring in the Malay Peninsula, mainly in Pahang State, and now reduced to about 300.

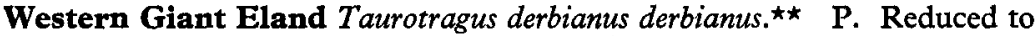
a few dozen animals in the interior of Guinea and the Ivory Coast.

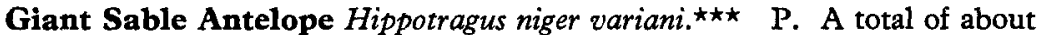
500 to 700 occupy the Luando Reserve and the Cangandala area in Angola.

Arabian Oryx Oryx leucoryx. ${ }^{\star \star}$ P. Still occurs in some of the remoter parts of Muscat and Oman, where may number 200 to 300, but no longer in the Eastern Arabian Protectorate. Eleven at Phoenix Zoo, Arizona, of which five belong to the Fauna Preservation Society, four to the World Wildlife Fund and two to the Zoological Society of London; eleven in two zoos in Saudi Arabia. Breeds readily in captivity; four born at Riyadh Zoo and two at Phoenix during past two years.

Walia Ibex Capra walie. ${ }^{\star \star}$ Possibly 200 inhabit the Simien plateau, Ethiopia.

\title{
MUST THE FIN WHALE BE EXTERMINATED?
}

THE outcome of the International Whaling Commission Meeting in Norway in June, though satisfactory for the conservation of blue and humpback whales, was disastrous for the Antarctic populations of the fin and sei whales. Owing to complete disagreement among the countries represented, no official agreement as to catch limits was reached at all. The Committee of Four Scientists had recommended a phased reduction of catches, of 4,000 blue whale units in 1964-65,3,000 in 1965-66 and 2,000 in $1967-68$, in order to allow recovery of stocks to begin in 1966-67. * Although the four Antarctic pelagic whaling countries (Russia, Japan, Norway, Holland) conferred together outside the conference and agreed a catch limit of 8,000 blue whale units (double the recommended number), conservationists are bound to take the most serious view of this flouting of scientific advice. This is perhaps the first time in history that four Governments have deliberately set out on a course of action that they know is likely to result in the extermination of at least one species of animal, the fin whale. Catches of fin whales in the Antarctic fell from 18,868 in 1962-63 to 13,870 in 1963-64, and are clearly likely to fall still further in 1964-65. Indeed, it looks as if the whaling industry has decided to cash in on the remaining stocks and then abandon whaling altogether, instead of taking the civilised decision to conserve stocks so that whaling can continue into the future. It is not surprising that the work of the Committee of Four Scientists in collaboration with FAO is likely to be suspended this year. There is little point in wasting scientists' time like this. A grave situation is also building up in the North Pacific, and it seems too much to hope that sanity will prevail there, when it has not done so in the Antarctic. Two welcome decisions were, however, made by the IWC, to extend complete protection to the blue whale south of $40^{\circ} \mathrm{S}$., and to continue for another five years the complete protection of the humpback in the southern hemisphere.

$\star$ One blue whale unit $=2$ fin or $2 \frac{1}{2}$ humpback or 6 sei whales. 